\title{
Peningkatan Kualitas Jaringan Pada Vehicle Ad-Hoc Network Menggunakan Algoritma Simple K-Means
}

\author{
Improved Network Quality on Ad-Hoc Network Vehicles using Simple K-Means
} Optimization

\author{
Ronald Adrian $^{1}$, Fahmizal $^{2}$, Nur Rohman Rosyid ${ }^{3}$ \\ ${ }^{1,2,3}$ Departemen Teknik Elektro dan Informatika Sekolah Vokasi \\ Universitas Gadjah Mada \\ e-mail : ${ }^{1}$ ronald.adr@ugm.ac.id, ${ }^{2}$ fahmizal@ugm.ac.id, ${ }^{3}$ nrohmanr@ugm.ac.id
}

\begin{abstract}
Abstrak
Vehicle Ad-hoc Network atau lebih dikenal dengan istilah VANET merupakan teknologi jaringan komunikasi data yang dapat diimplementasikan pada kendaraan di jalan raya. Jaringan komunikasi data yang diterapkan pada VANET memiliki beberapa permasalahan. Salah satu permasalahan yang terjadi adalah penjaminan kualitas jaringan yang belum handal. Hal ini disebabkan oleh karakteristik kendaraan pada VANET yang bergerak secara dinamis. Kecepatan dan posisi kendaraan membuat koneksi jaringan menjadi tidak stabil. Untuk mengatasi permasalahan tersebut dalam artikel ini diusulkan sebuah aturan-aturan baru yang dikombinasikan dengan algoritme simple k-means. Algoritme tersebut sering digunakan dalam pengelompokan data. Akan tetapi perlu penambahan dan modifikasi algoritme tersebut agar dapat diterapkan secara optimal pada VANET. Hasil yang didapatkan pada penelitian ini menunjukkan bahwa pemimpin cluster atau centroid pada simple k-means bisa digantikan oleh kandidat lain yang memiliki kualitas jaringan lebih baik. Pergantian ini ditujukan untuk mendapatkan pemimpin kluster yang benar-benar terbaik bagi anggota klusternya.
\end{abstract}

Kata kunci-VANET, K-Means, Cluster

\begin{abstract}
Vehicle Ad-hoc Network or better known as VANET is a data communication network technology that can be implemented on vehicles on the highway. The data communications network applied to VANET has several problems. One of the problems that occur is the guarantee of network quality that has not been reliable. This is due to the dynamically moving characteristics of VANET vehicles. Speed and position of the vehicle makes the network connection becomes unstable. To solve the problem in this article, author proposed a new rules combined with simple $k$-means algorithm. The algorithm is often used in grouping data. However, it is necessary to add and modify the algorithm so that it can be applied optimally on VANET. The results obtained in this study indicate that cluster leaders or centroid on simple k-means can be replaced by other candidates who have better network quality. This change is aimed at getting the cluster leader who really best for this cluster members.
\end{abstract}

Keywords - VANET, K-Means, Cluster

\section{PENDAHULUAN}

VANET merupakan teknologi terbaru dalam dunia transportasi yang mengimplementasikan jaringan komputer pada kendaraan-kendaraan yang ada di jalan raya. VANET merupakan singkatan dari vehicle ad-hoc network. Jaringan ad-hoc merupakan jaringan yang terdistribusi secara nirkabel. Teknologi VANET merupakan pengembangan teknologi

MANET (mobile ad-hoc network). VANET memiliki karakter yang berbeda dengan MANET [1]. Node pada VANET bergerak secara dinamis dengan kecepatan tertentu dan pada 
posisi tertentu sedangkan pada MANET, node diam dan tidak melakukan pergerakan dengan kecepatan tertentu.

Penelitian tentang VANET sedang berkembang pesat dewasa ini. Mulai dari koneksi jaringan antar kendaraan atau koneksi jaringan kendaraan ke infrastruktur atau lebih dikenal dengan sebutan road side unit (RSU) [2]. Penelitian berkembang mulai dari physical, network sampai pada layer application [3]. Penelitian terkini tentang VANET dalam lingkup jaringan adalah pencarian sebuah metode yang efektif untuk mendapatkan kualitas jaringan yang baik. Kualitas jaringan yang baik tersebut dapat dibuktikan dengan throughput yang tinggi dan bit error rate (BER) yang rendah.

Metode yang akan digunakan pada penelitian ini adalah pengelompokan kendaraan. Metode pengelompokan menggunakan algoritme simple k-means. Metode tersebut sudah sangat sering digunakan dalam pengelompokan data akan tetapi belum pernah dicoba untuk pengelompokan kendaraan yang sifat datanya sangat kompleks. Data diolah pada VANET melingkupi kecepatan masing-masing kendaraan yang berubah-ubah, posisi kendaraan, jarak kendaraan satu dengan yang lainnya dan jarak kendaraan dengan RSU. Pada metode pengelompokan atau sering dikenal dengan metode clustering akan menghasilkan centroid pada setiap clusternya. Centroid inilah yang akan diadopsi sebagai pemimping dalam sebuah grup yang berisi banyak kendaraan.

Artikel ini memiliki susunan bab sebagai berikut. Metode penelitian dijelaskan secara ringkas pada bab 2. Hasil dan pembahasan dilakukan secara mendalam pada bab 4 dan pada bab terakhir kesimpulan dari penelitian yang telah dilakukan.

\section{METODE PENELITIAN}

Tahan penelitian secara umum melibatkan tahap perancangan simulasi, pengujian simulasi dengan melibatkan parameter-parameter yang telah ditentukan dan analisis data yang dilakukan berdasarkan hasil penelitian yang telah dikerjakan.

Data yang digunakan pada penelitian ini dihasilkan dari simulasi yang melibatkan 10 mobil. Mobil tersebut bergerak dengan kecepatan acak pada 3 jalur yang searah. Kecepatan masing-masing diberi batasan antara $10 \mathrm{~ms}(36 \mathrm{~km} / \mathrm{jam})$ sampai $30 \mathrm{~ms}(108 \mathrm{~km} / \mathrm{jam})$. Parameter penelitian secara lengkap ditampilkan dengan ringkas pada tabel 1.

Tabel 1 Parameter Pengujian

\begin{tabular}{|l|l|}
\hline Parameter & Nilai \\
\hline Jumlah Kendaraan & 10 buah \\
\hline Kecepatan & $10 \mathrm{~ms}-30 \mathrm{~ms}$ \\
\hline RSU & 2 buah \\
\hline Jangkauan Sinyal RSU & 300 meter \\
\hline Lebar Jalan & 10 meter \\
\hline Panjang Jalan & 1000 meter \\
\hline Modulasi & 64-QAM \\
\hline Path Loss & Rayleigh \\
\hline Protokol & $802.11 \mathrm{p}$ \\
\hline
\end{tabular}

Jalan yang dipergunakan memiliki panjang 1000 meter x lebar 10 meter. Pada simulasi dilakukan penskalaan dengan perbandingan 1:2 sehingga menjadi setengah dari nilai sesungguhnya. Maksud dari penskalaan ini agar dapat lebih melihat secara detail pergerakan kendaraan karena resolusi monitor yang dipergunakan untuk pengujian ini terbatas. 
Metode penelitian yang dikerjakan pada penelitian ini memiliki beberapa tahapan seperti yang terlihat pada gambar 1. Gambar tersebut menunjukkan langkah-langkah pengerjaan mulai dari scan data kendaraan yang dilakukan oleh sistem di masing-masing RSU.

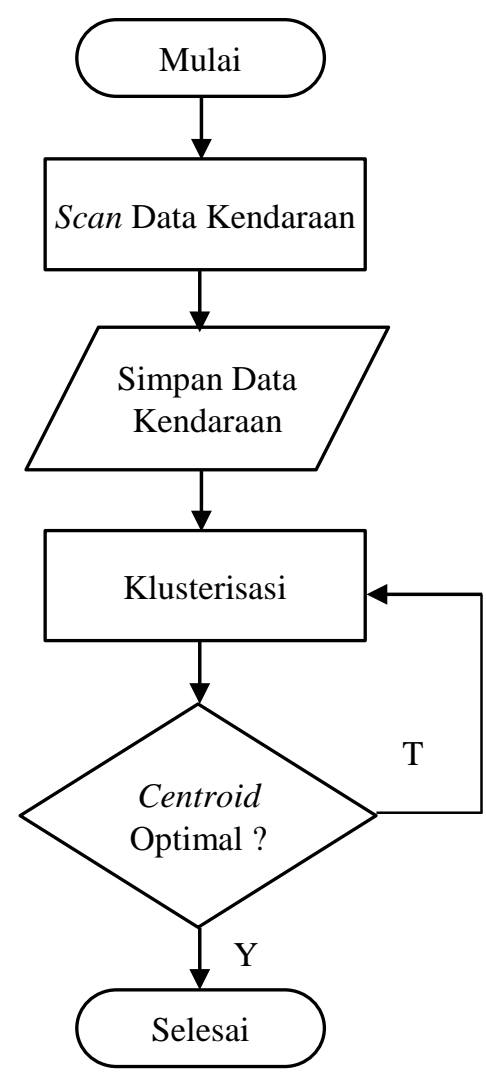

Gambar 1 Flowchart Penelitian

Setiap RSU seperti halnya tower selular dapat melakukan passive scanning terhadap device yang berada dalam jangkauannya walaupun tidak dalam posisi melakukan koneksi [4]. Teknik ini juga sering digunakan dalam localization jaringan nirkabel yang tanpa menggunakan GPS. Langkah selanjutnya adalah melakukan penyimpanan data kendaraan yang meliputi posisi, kuat sinyal, kecepatan masing-masing kendaraan dan throughput yang didapatkan dari hasil triggered ping testing. Setelah mendapatkan semua data tersebut maka akan dilakukan klusterisasi secara otomatis pada RSU. RSU yang berdekatan akan saling tukar menukar informasi ini sehingga meminimalkan resiko kesalahan pada saat klusterisasi yang dilakukan oleh beberapa RSU pada waktu yang sama. Hal ini mengadopsi konsep jaringan $4 \mathrm{G}$ saat melakukan pemilihan base station yang akan digunakan oleh pengguna smartphone.

Proses pengelompokan kendaraan menjadi hal terpenting pada penelitian ini. Proses ini melibatkan penggunaan algoritme simple K-Means yang telah dilakukan sedikit modifikasi pada centroid. Algoritme simple K-Means ini merupakan algoritme pengelompokan berdasarkan kedekatan nilai anggota dengan nilai centroidnya. Nilai centroid ini dapat berubah-ubah sesuai dengan keadaan nilai-nilai yang ada disekitarnya. Setiap iterasi yang dilakukan dapat mengubah nilai centroid yang sudah ada.

Algoritme ini secara umum sering dipergunakan pada data mining yang bertujuan untuk mendapatkan knowledge baru dalam sebuah pengelompokan. Akan tetapi algoritme ini belum pernah dilakukan penelitian lebih lanjut pada VANET yang memiliki karakter data berubah-ubah secara dinamis. Melalui penelitian ini penulis ingin memberikan informasi tentang penggunaan algoritme ini pada lingkup pengujian VANET. 
Gambar 2 merupakan pemodelan pergerakan kendaraan yang sedang berjalan pada jalan raya 3 jalur yang searah. Pemodelan seperti ini dipergunakan pada penelitian VANET di luar negeri dimana tingkah laku pengendara mobil tidak terlalu ekstrem seperti yang ada di Indonesia [5]. Kecepatan kendaraan dibuat acak sehingga membuat kondisi simulasi mendekati sesungguhnya. Model propagasi yang digunakan adalah free space path loss (FSPL) tanpa adanya gangguan dan meniadakan efek fading ataupun shadowing. Pemodelan seperti ini sering dijumpai di jalan bebas hambatan.
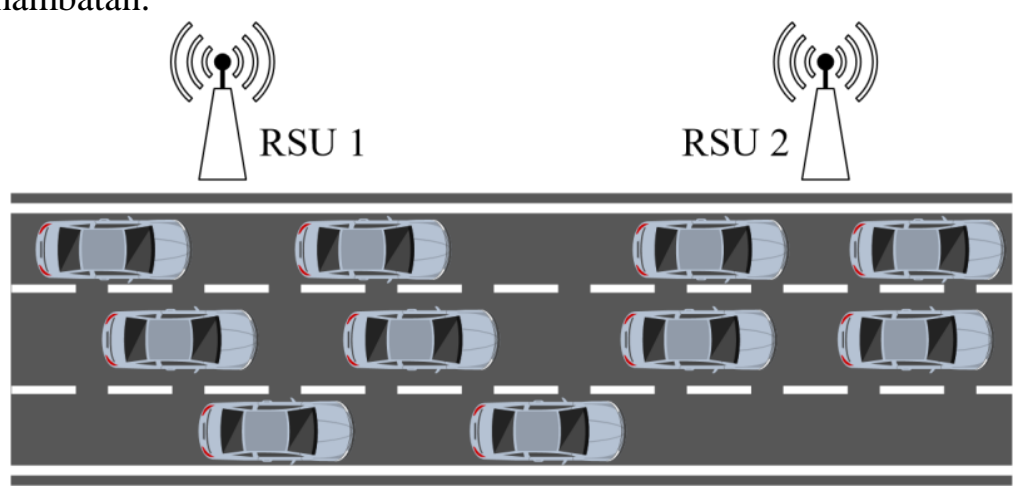

Gambar 2 Pergerakan Mobil pada Jalan Raya

\section{HASIL DAN PEMBAHASAN}

Pemodelan pergerakan mobil pada bab sebelumnya disimulasikan pada matlab dengan menggunakan parameter-parameter antara lain adalah kecepatan yang acak antara $36 \mathrm{~km} / \mathrm{jam}$ sampai $90 \mathrm{~km} / \mathrm{jam}$ [6], posisi kendaraan yang acak tetapi tetap mematuhi aturan pergerakan 3 jalur dan posisi RSU yang diposisikan secara statis pada pinggir jalan seperti halnya menara komunikasi selular. Pemodelan pergerakan ini secara visual ditunjukkan pada gambar 3.

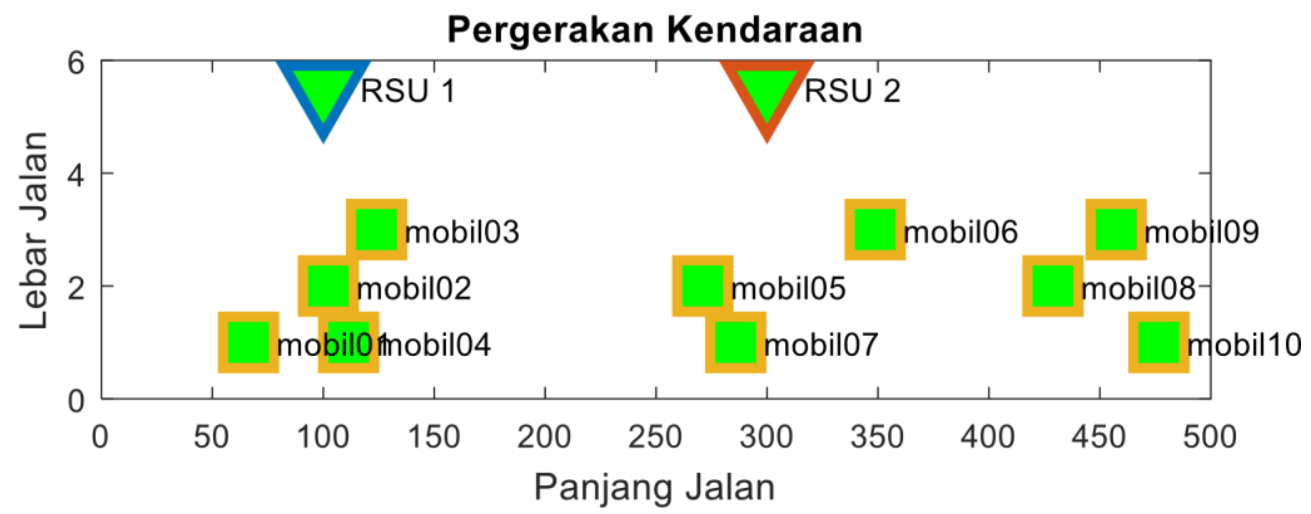

Gambar 3 Simulasi Pergerakan Kendaraan

Setelah pemodelan dijalankan maka sistem yang ada pada RSU akan bekerja. Poin penting yang ada disini adalah pengelompokan data berdasarkan algoritme simple k-means. Algoritme ini sangat sederhana hanya dengan menggunakan pemilihan kluster berdasarkan kedekatan jarak antar partikelnya [7].

$$
d\left(x_{j}, c_{j}\right)=\sqrt{\sum_{j=1}^{n}\left(x_{j}-c_{j}\right)^{2}}
$$


Persamaan 1 merupakan persamaan dasar simple k-means yang diterapkan pada proses klusterisasi di penelitian ini. Dimana $d$ adalah jarak antara sebuah data pertama dengan centroid pertama, kemudian dilakukan iterasi seterusnya sampai mendapatkan centroid yang optimal. Parameter $j$ merupakan jumlah total data. Dalam kasus ini adalah jumlah kendaraan yang disimulasikan yaitu berjumlah 10 kendaraan. Simbol $c$ merupakan centroid dan $x$ adalah isi datanya.

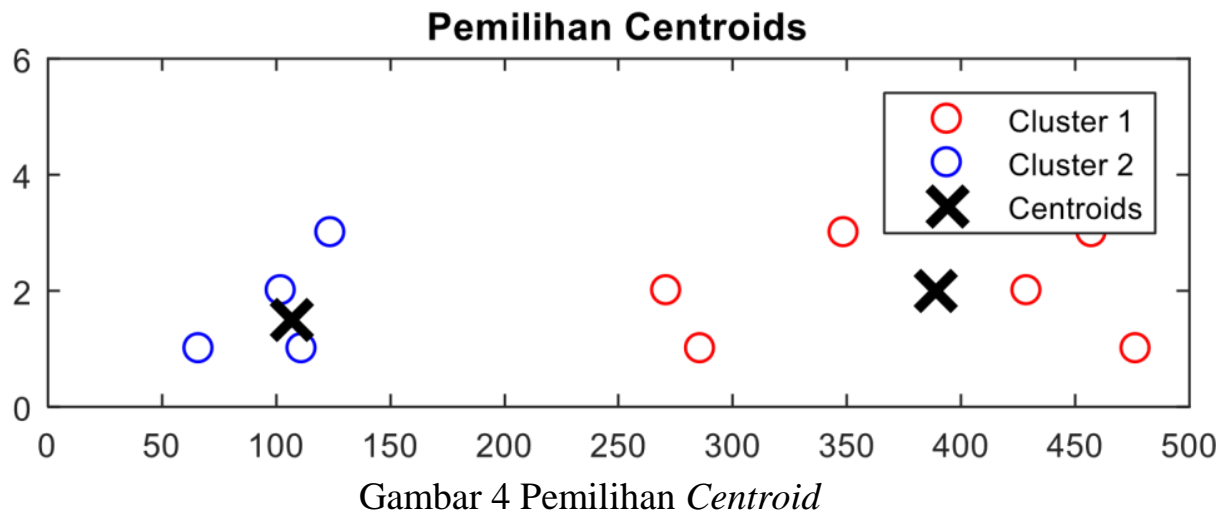

Gambar 4 merupakan hasil perhitungan algoritme k-means dengan masukan 2 kelompok data. Warna merah menunjukkan bahwa mobil masuk kedalam kategori kluster 1 sedangkan warna biru menunjukkan bahwa mobil tergabung dalam keanggotaan kluster 2. Pada percobaa tersebut terlihat bahwa anggota kluster 1 terdiri dari 6 mobil dan anggota kluster 2 terdiri dari 4 mobil. Dalam kondisi normal mobil terdekat dengan centroid akan dipilih sebagai pemimpin kluster atau cluster head $(\mathrm{CH})$.

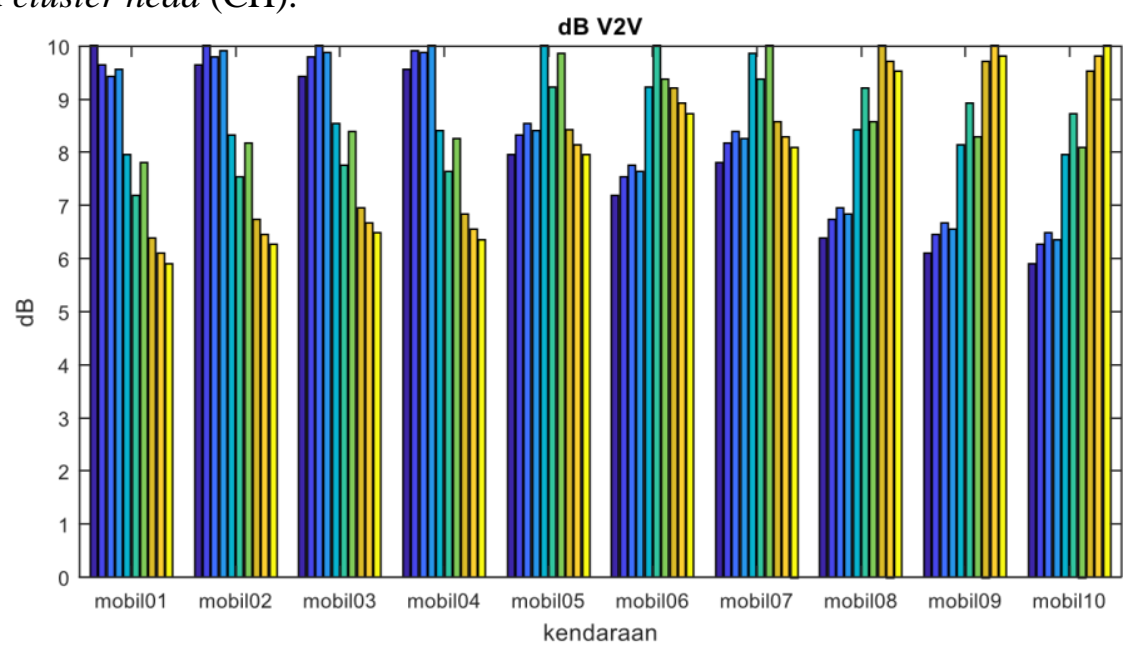

Gambar 5 Pengukuran Kuat Sinyal antar Kendaraan

Keterbaruan yang didapatkan pada penelitian ini adalah modifikasi pemilihan $\mathrm{CH}$ dengan mempertimbangkan kuat sinyal yang discan oleh masing-masing piranti nirkabel yang ada pada setiap kendaraan. Data pengukuran kuat sinyal diperlihatkan secara lengkap pada gambar 5. Gambar tersebut menunjukkan kuat sinyal dari mobil 1 ke mobil 2 sampai 10 begitupun seterusnya sehingga semua mobil dapat terhitung data kuat sinyalnya. 


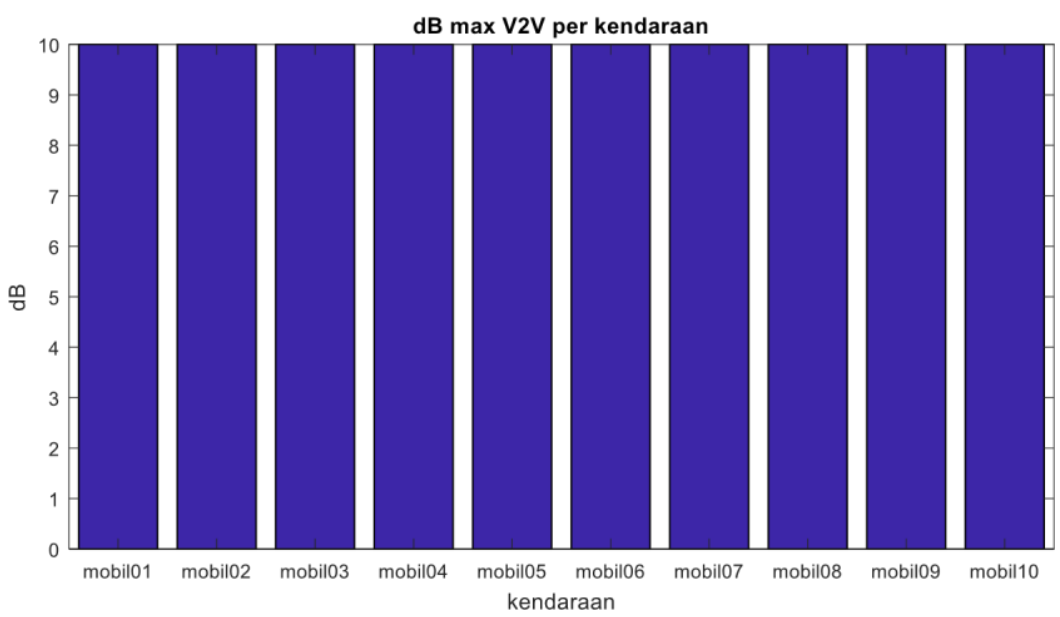

Gambar 6 Pemilihan Maksimum Kuat Sinyal per Kendaraan

Kuat sinyal terbaik akan dijadikan pedoman dalam memilih pemimpin kluster. Apabila didapatkan kuat sinyal yang hampir atau sama kuatnya seperti yang tertampil pada gambar 6 maka diperlukan pertimbangan lainnya. Pemilihan dilanjutkan dengan triggered ping testing. Hal ini dilakukan secara broadcast dengan menggunakan sampel paket dan menghasilkan data pada gambar 7.

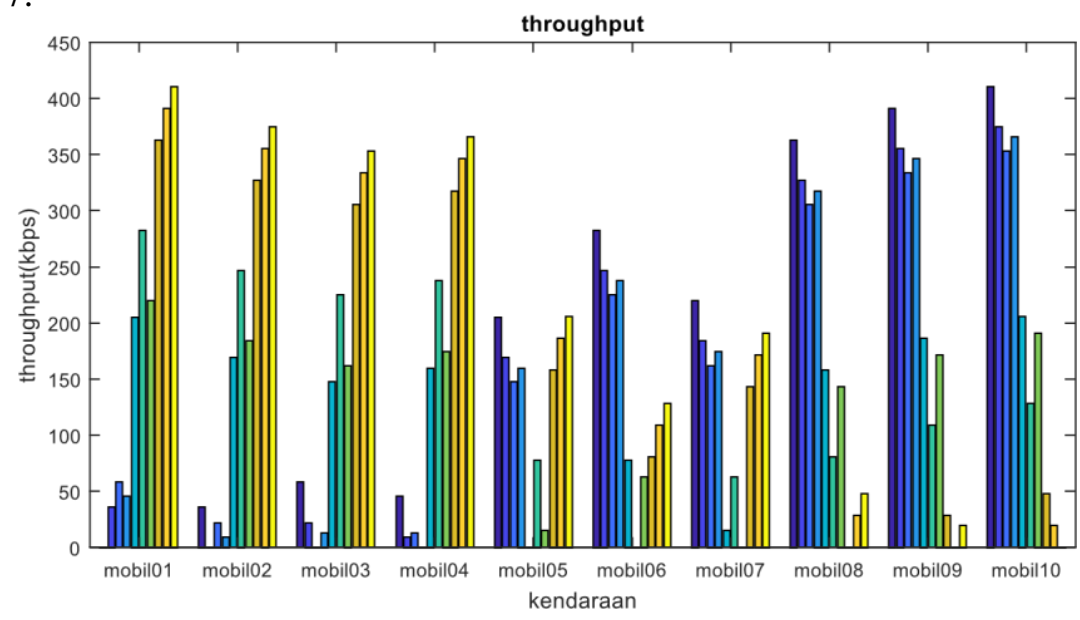

Gambar 7 Pengukuran Throughput antar Kendaraan

Throughput yang didapat diolah kembali dengan aturan maksimum throughput yang akan dipakai sebagai pertimbangan untuk pemilihan pemimpin kluster. Data dari maksimum throughput yang ada pada setiap kendaraan dapat dilihat pada gambar 8. Throughput ini merupakan parameter yang penting dalam penentuan performa jaringan. Throughput yang tinggi akan menjamin data terkirim dengan baik [8]. 


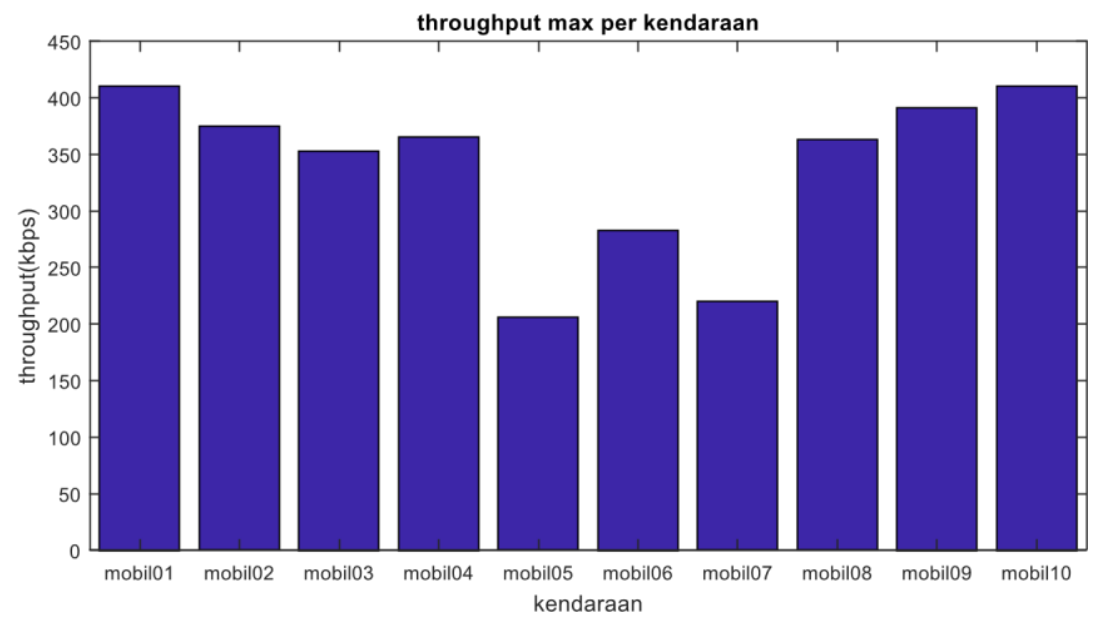

Gambar 8 Pemilihan Throughput Maksimum per Kendaraan

Hasil data pada gambar 8 menunjukkan bahwa throughput maksimal ditunjukkan pada mobil 1 dan mobil 10. Jika dilihat dari hasil klusterisasi sebelumnya anggota kluster 1 adalah mobil 5 sampai 10 sendangkan anggota kluster 2 adalah mobil 1 sampai 4 . Dengan kondisi tersebut maka hasil sementara yang didapatkan adalah mobil 1 merupakan pemimpin kluster 2 dan mobil 10 merupakan pemimpin kluster 1. Akan tetapi proses pemilihan ini belum selesai karena masih ada satu parameter lagi yang harus dipertimbangkan oleh masing-masing kendaraan yaitu kuat sinyal terhadap masing-masing RSU yang ada disekitarnya.

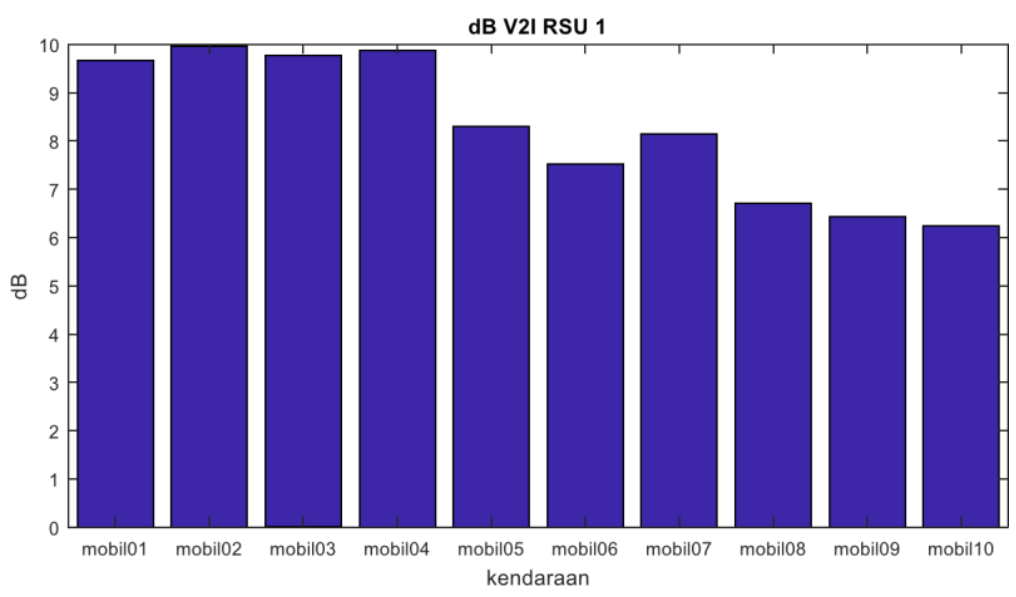

Gambar 9 Pengukuran Kuat Sinyal per Kendaraan ke RSU 1

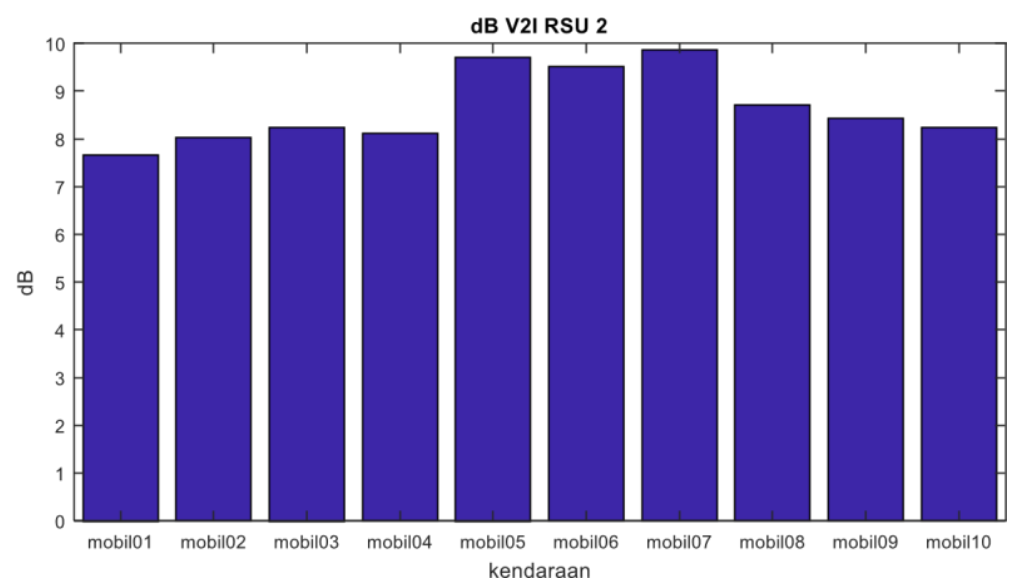

Gambar 10 Pengukuran Kuat Sinyal per Kendaraan ke RSU 2 
Gambar 9 menunjukkan data pengukuran kuat sinyal dari masing-masing mobil ke RSU 1. Begitupun juga dengan gambar 10. Menunjukkan hasil pengukuran kuat sinyal masing-masing mobil ke RSU 2. Dalam tahap ini RSU yang dalam jangkauan 300 meter (standar jangkauan RSU 802.11p) dengan RSU lain akan melakukan tukar informasi data sehingga dimungkinkan untuk melakukan komputasi bersama dalam rangka menentukan RSU mana yang berhak berkomunikasi dengan pemimpin kluster dan apakah pemimpin kluster sementara bisa digantikan dengan kandidat lain yang lebih optimal. Komparasi perbandingan tersebut menunjukkan bahwa terjadi perpindahan kepemimpinan dari kluster 2 yaitu dari mobil 1 (pemimpin sementara) berpindah ke mobil 2 (pemimpin berdasarkan kuat sinyal RSU 1) dan kluster 1 dari mobil 10 (pemimpin sementara) berpindah ke mobil 7 (pemimpin berdasarkan kuat sinyal RSU 2). Hal ini menunjukkan bahwa kluster 1 dengan anggota mobil 5 sampai 10 terkoneksi ke jaringan RSU 2 melalui mobil 7 dan kluster 2 dengan anggota mobil 1 sampai 4 terkoneksi ke RSU 1 melalui mobil 2.

Proses pengelompokan ini tentu saja dilakukan validasi dengan menghitung bit error rate (BER) untuk sampel 1 mobil pemimpin kluster dengan berbagai tingkat gangguan yang bisa terjadi di FSPL. Persamaan 2 merupakan persamaan bit error rate yang sering digunakan dalam validasi performa jaringan komunikasi.

$$
B E R=\frac{1}{2}(1-\operatorname{erf}) \sqrt{E_{b} / N_{o}}
$$

Persamaan BER tersebut memiliki parameter $\operatorname{er} f$ sebagai fungsi error, $E_{b}$ sebagai energi yang dibutuhkan dalam satu bit (Joules/bit) dan $N_{o}$ sebagai Noise Power dalam bandwidth $1 \mathrm{~Hz}$ [9]. Sedangkan hasil pengukuran yang dilakukan terlihat pada gambar 11.

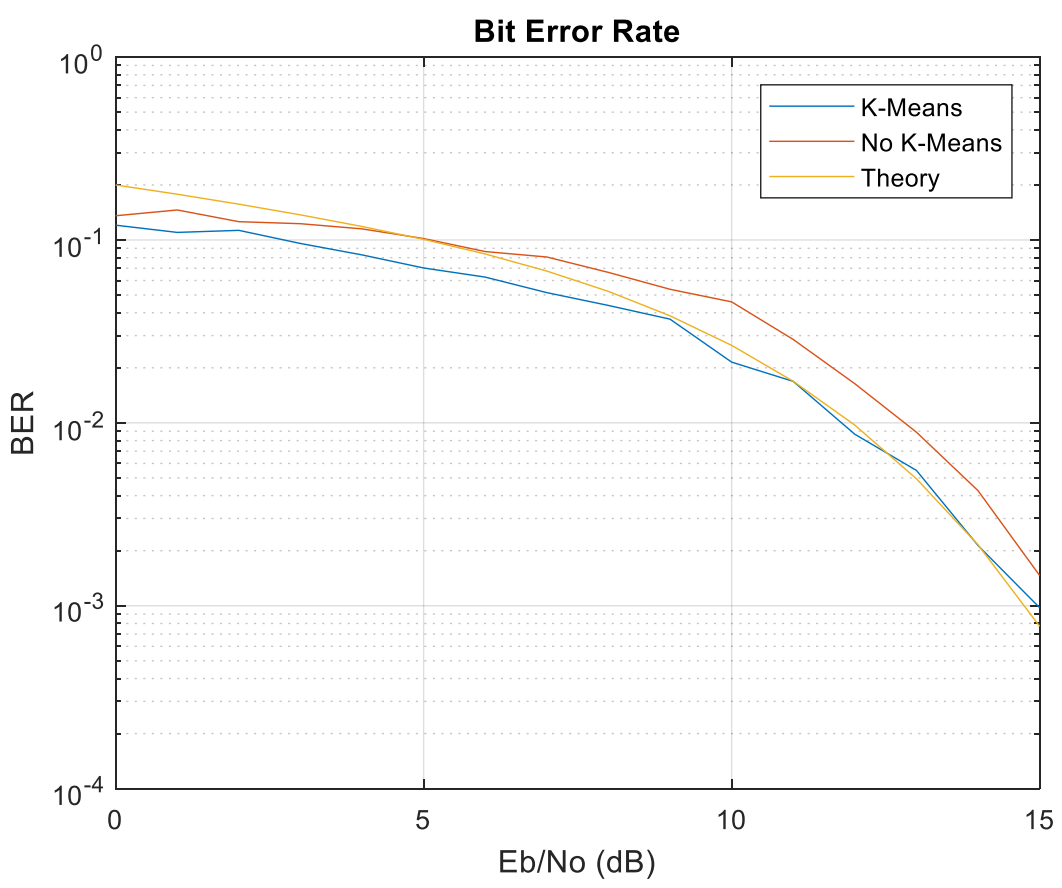

Gambar 11 BER Pemimpin Kluster

Hasil yang didapat menunjukkan bahwa BER setelah dilakukan klusterisasi dengan simple k-means mengalami peningkatan dibandingkan tanpa menggunakan metode klusterisasi. Peningkatan terlihat cukup signifikan dan mendekati kurva teori BER dimana kurva ini dibuat dengan kondisi ideal sesuai teori tanpa adanya bit yang error. 


\section{KESIMPULAN}

Penelitian ini menghasilkan sebuah skema baru dalam teknik klusterisasi data dengan menambahkan aturan pada algoritme simple k-means. Proses pemilihan melibatkan beberapa parameter yang dapat menyebabkan pemimpin kluster berpindah ke kandidat lain dalam anggota klusternya. Hal ini dimungkinkan karena untuk menjadi seorang pemimpin kluster diperlukan kualitas jaringan terbaik karena pemimpin kluster akan memberikan sumber dayanya ke anggota yang lain. Hasil validasi menunjukkan bahwa metode klusterisasi yang diusulkan layak untuk diterapkan pada VANET.

\section{SARAN}

Saran pada penelitian ini adalah mengembangkan pemodelan simulasi data pada tingkat kerumitan tertentu yang mewakili keadaan jalan dan kendaraan sesungguhnya. Pemodelan dapat dilakukan sesuai dengan kondisi jalan dan kepadatan lalu lintas yang ada.

\section{DAFTAR PUSTAKA}

[1] N. Loulloudes, G. Pallis, and M. D. Dikaiakos, "The Dynamics of Vehicular Networks in Urban Environments," ArXiv10074106 Cs, Jul. 2010.

[2] H. Boeglen, B. Hilt, P. Lorenz, J. Ledy, and A. M. Poussard, "A survey of V2V channel modeling for VANET simulations," in 2011 Eighth International Conference on Wireless On-Demand Network Systems and Services, 2011, pp. 117-123.

[3] M. Dixit, R. Kumar, and A. K. Sagar, "VANET: Architectures, research issues, routing protocols, and its applications," in 2016 International Conference on Computing, Communication and Automation (ICCCA), 2016, pp. 555-561.

[4] R. Adrian, I. W. Mustika, and others, "Modeling Base Station Selection in Open Access Picocell Networks Using Particle Swarm Optimization," 2015.

[5] P. Santi, "Mobility Models for Vehicular Networks," in Mobility Models for Next Generation Wireless Networks:Ad Hoc, Vehicular and Mesh Networks, Wiley Telecom, 2012, p. 448-.

[6] D. Zelikman and M. Segal, "Reducing Interferences in VANETs," IEEE Trans. Intell. Transp. Syst., vol. 16, no. 3, pp. 1582-1587, Jun. 2015.

[7] F. Qin, Y. Zhang, G. Yue, X. Liu, H. Su, and P. F. Zhang, "Atherosclerotic Plaque Pathological Analysis by Unsupervised K-means Clustering (February 2018)," IEEE Access, vol. PP, no. 99, pp. 1-1, 2018.

[8] R. Adrian, "Optimasi Cost pada Open Shortest Path First di Jaringan Software Defined-Network," Techno Com, vol. 16, no. 4, pp. 421-434, 2017.

[9] Y. Fan and Z. Zilic, "BER Testing of Communication Interfaces," IEEE Trans. Instrum. Meas., vol. 57, no. 5, pp. 897-906, May 2008. 